\title{
CONFLICTO, VIOLENCIA Y NO VIOLENCIA
}

Karlos Navarro*

\begin{abstract}
Resumen
Este ensayo ha sido elaborado para ofrecer un marco de válida referencia conceptual que ayude a los lectores a obtener una mejor comprensión de las más importantes corrientes del pensamiento social y político sobre el conflicto, la violencia y la no violencia.
\end{abstract}

Se resumen, a grandes rasgos, las orientaciones claves de las más importantes tendencias que han activado la historia universal de las teorías socio-políticas, sobre todo en la cultura occidental. Pero se recalcan las innovadoras visiones que han proliferado, en los últimos treinta años, dentro de las amplias perspectivas abiertas por un grupo creciente de estudiosos que concentran los esfuerzos en la investigación científica de la cultura de paz.

En este contexto interpretativo se analizarán diversos enfoques teóricos sobre la naturaleza y orígenes del conflicto y la violencia. También se expondrán varias concepciones que afectan su clasificación y categorías, de acuerdo con la importancia dada a diferentes factores.

Finalmente se presentará una sinopsis de algunas nuevas ideas que van adquiriendo vigencia creciente en el campo de la resolución o transformación de conflictos. Se sintetizarán sus líneas directrices para facilitar la valoración de los principios y procesos afectados. ${ }^{1}$

Igualmente se elaborará un esquema de las nuevas orientaciones que se remontan directamente al modelo de Gandhi y que se entroncan en el rico panorama de las filosofias orientales sobre el orden social y las obligaciones éticas. Tal será el marco explicativo de las estrategias defensivas de la no-violencia, de sus conceptos, principios y modos de acción. ${ }^{2}$

Palabras clave: conflicto, violencia, no vilencia, cultura de paz, desarrollo

Key words: conflict, violence, nonviolence, culture of peace, development

\section{Marco conceptual para el analisis intepretativo de la historia}

La historia universal del pensamiento político y social ha girado en torno de dos grandes ejes conceptuales y éticos: el orden y el conflicto. Esta dualidad temática permanente expresa la dicotomía radical del ser y del deber ser. Enuncia la relación dialéctica y necesaria que existe entre la realidad fáctica y la otra realidad complementaria de las normativas morales. La realidad axiológica de los derechos, deberes y responsabilidades individuales y colectivas.

Todas las épocas y culturas del mundo han vivido la experiencia única y constante

\footnotetext{
Karlos Navarro, Doctor en Derecho Admijnstrativo, Universidad de Salmanca. Docente de derecho administrativo.UNAN-Managua. Entre las obras citadas en la bibliografía,, tienen especial vigencia en este tema los aportes de Lederech, Quan y Hood, Grasa.

2 El modelo de Gandhi se analiza detalladamente en Burrowes y en las recopilaciones recogidas en Justice Without Violence y Approaches to Peace
} 
del conflicto y la violencia. Esta vivencia ha suscitado una gran variedad de preguntas articuladas por un sinnúmero de pensadores, alrededor de esas dos experiencias fundamentales: ¿qué son el conflicto y la violencia? ¿Cómo se definen sus elementos y se clasifican sus tipologías? ¿Cuáles son sus orígenes y naturalezas? ¿Son fenómenos ineludibles? ¿Están generadas por fuerzas externas: los dioses, el cosmos, el destino, la evolución histórica, algunas configuraciones de las relaciones humanas, por ciertos elementos del entorno vital, por determinados movimientos de materia o energía, por las distribuciones del poder o las estructuras de los sistemas? ¿O son impulsados, más bien, desde dentro de los seres humanos, por sus instintos genéticos, sus intereses, sus ideas, sus valores o sus necesidades? ¿Cuál es la conexión entre conflicto y cambio; conflicto y desarrollo; conflicto y obediencia; conflicto y seguridad; conflicto

32 y poder; conflicto y autonomía; conflicto y justicia; conflicto e individuos, sociedad y mundo? ¿Cómo se valoran el conflicto y la violencia? ¿Son buenos o malos? ¿Es posible y deseable su eliminación? ¿Es posible su transformación y cuáles son los procesos y mecanismos para lograrla?

Entre todas esas interrogantes del pensamiento universal, destacan hoy, con creciente vigor y urgencia, las que se centran en la interacción recíproca de la violencia y la no violencia; del conflicto, la guerra y la paz.

\section{Naturaleza y tipología del conflicto}

El conflicto ha sido percibido de formas diferentes. Por ello se han dado una gran variedad de definiciones que contienen los términos sinónimos de combate, lucha, pelea o problema. También se menciona con frecuencia la coexistencia de tendencias contradictorias. Probablemente la descripción más adecuada sea la de "una situación o estado de interacción entre personas y colectivos, a nivel intra-, inter-trans-nacional o mundial, que poseen intereses, ideas, valores, necesidades o fines incompatibles". ${ }^{3}$

Desde un punto de vista funcional, es evidente que los conflictos predominan en todos los ámbitos de la actividad humana $\mathrm{y}$ afectan substancialmente a todas las relaciones de género, ecología, cultura, economía, política y sociedad. El conflicto es, sin duda, un fenómeno inescapable y universal. Sus manifestaciones concretas adquieren una vasta amplitud de modalidades. A veces, como subrayan los economistas, se despliega como una pugna por conseguir un espacio de participación en la posesión y control de los recursos escasos. A veces, como han observado otros pensadores, las incompatibilidades que causan los conflictos se derivan de metas excluyentes entre las partes en litigio. A veces el conflicto aparece como un choque de voluntades entre actores contendientes o como una lucha competitiva para lograr resultados deseados por ambos contrincantes.

Es importante destacar, desde el inicio, la conexión intrínseca que existe entre conflicto y cambio, ya que de modoimplícito o explícito, casi todos los conflictos reflejan una contienda por defender o transformar el status quo. Y también se debe resaltar la inherente unión del conflicto con el clima emocional, de tensión, desconfianza, descontento e inseguridad provocados por algún tipo de privación, frustración o exclusión.

La naturaleza del conflicto ha sido objeto de una enorme variedad de interpretaciones científicas. Entre ellas vamos a indicar unas cuantas que merecen especial mención. Varios autores han puesto énfasis en la

3 Esta es una definición propia extraida eclécticamente de diversas definiciones ofrecidas por otros autores. 
importancia del contexto cultural para el análisis de los conflictos. Muchas veces, se crean $\mathrm{o}$, al menos, se exacerban $\mathrm{y}$ deterioran los conflictos por diferencias de comunicación, información y percepción. De ahí que se atribuya tanta importancia a los procesos de socialización, positiva o negativa, en el análisis de los conflictos.

Otros pensadores, siguiendo las orientaciones de Parsons, han definido al conflicto como una aberración sistémica que exhibe síntomas de disfuncionalidad en el Proceso Social. Desde un punto de vista similar, pero más afín a la sicología social, algunos autores han descrito la "historia natural del conflicto" como signos de patología social y lo han estudiado desde una perspectiva de epidemia semiológica. ${ }^{4}$

Entre las numerosas aportaciones de nuevos enfoques en el pensamiento moderno, con respecto a la naturaleza del conflicto, es preciso enumerar dos ideas que poseen prestancia y alcance singulares. La primera es que hay muchos conflictos cuya naturaleza no radica en las interacciones de personas concretas, sino en su condición misma de incompatibilidad estructural resultante de las interacciones del propio sistema. Esta es una idea que contribuye a una interpretación nueva, de enorme profundidad y riqueza para la investigación de los conflictos sociales. Entre los estudiosos contemporáneos que han colaborado notablemente esta idea, es necesario citar a John Burton, (Inglaterra), Johan Galtung, (Noruega), Peter Wallensteen (Suecia) y Felipe Mc Gregor (Perú). ${ }^{5}$
La otra idea novedosa, de igual dinamismo y prestancia, está íntimamente ligada a la anterior. Este conflicto estructural y sistémico es, al mismo tiempo, el producto de la extremada insatisfacción de necesidades humanas básicas. Este conflicto se define así como una patología de los sistemas sociales globales. Al no satisfacer las necesidades fundamentales del ser humano, en cada una de las esferas, biológicas, ecológicas, económicas, ideológicas, políticas y espirituales, las relaciones de poder estructural, crean condiciones globales de antagonismos que se convierten en problemas globales. Estos problemas estructurales no resueltos, se transforman en crisis globales que afectan profunda y negativamente al conjunto de las relaciones sistémicas, sus elementos, instituciones, funciones y estructuras.

\section{Naturaleza y tipología de la violencia}

A pesar de los estrechos vínculos que se dan entre la naturaleza del conflicto y de la violencia y a pesar del carácter común de su presencia omnímoda en la historia universal, es necesario aclarar las importantes diferencias que distinguen a ambos conceptos. Como veremos más tarde, el conflicto no es necesariamente un fenómeno de características negativas. Por medio de canales adecuados se puede restringir, moderar e incluso transformar, integrándolo en un ámbito superior, una comunidad de intereses compartidos por las partes en conflicto.

4 Ver Quan- Hood para una elaboración sistemática de esta hipótesis

5 Arenal (sección 4 B pp. 338-362) ofrece una excelente interpretación de las contribuciones científicas de estos y otros investigadores pioneros. Las notas presentan las referencias bibliográficas claves. Para el último pensamiento de Galthun ver su reciente libro Peace by peaceful Means, Sage-OPRI, 1996. Es de notar el énfasis puesto en la violencia cultural Además de esta sección, la Introducción del Arenal también estudia los aportes de Burton en otros capítulos. De especial interés son los comentarios en las pp. 233-4 y 356-9. Los aporte de Galthun se analizan sobre todo en las pp. 349-55. Como complemento a la interpretación magistral de Arenal se recomiendan las referencias de Padilla, en especial sobre Wallensteen y las de Burrowes (passim) sobre Burton. Para Mac Gregor ver la obra mencionada. 
Laviolencia, porelcontrario, representa una etapa extrema del conflicto incontrolado. La violencia, que es siempre una realidad nociva, conlleva una multitud de efectos perniciosos, y muchas veces cruentos. Las definiciones de violencia más comunes, dentro del pensamiento social tradicional, siguen los postulados prevalentes de las escuelas inadecuadamente llamadas realistas. Incluyen elementos personalizantes de intencionalidad $y$ voluntarismo que inciden en la amenaza o el ejercicio de la fuerza física o moral; la coacción, las sanciones y los mecanismos coercitivos.

Las nuevas corrientes del pensamiento contemporáneo sobre la paz han contribuido a impartir nuevas visiones conceptuales que ensanchan y dinamizan, de modo radical, nuestra comprensión de la violencia, su naturaleza y sus categorías.

De esa forma, el análisis y la interpretación de la violencia abarcan hoy, unas perspectivas teóricas de mayor amplitud $\mathrm{y}$ vigencia. La violencia se define ahora no sólo como el ejercicio explícito y directo de la fuerza para obtener alguna meta, contra la voluntad de alguien. La nueva definición de la violencia incluye también, la aplicación indirecta, no fácilmente perceptible y quizás no necesariamente consciente o inmediatamente voluntaria, de la fuerza estructural que se traduce en explotación, imposición y dominio. ${ }^{6}$

En esta nueva concepción de la violencia, se pone énfasis en su naturaleza sistémica, estructural, implícita y posiblemente oculta. Es una violencia que tiene sus raíces en las mismas estructuras sociales, es decir en las posiciones desiguales de poder entre los elementos y actores sistémicos.
Proviene pues, de las configuraciones de la estratificación, las relaciones jerárquicas que unos actores mantienen sobre otros $y$ que se manifiestan en expresiones culturales de dominio, marginación, impotencia y exclusión de las víctimas de esa violencia.

Esta nueva visión de la violencia resalta además la enorme transcendencia que tienen sus inherentes dimensiones éticas para facilitar su cabal comprensión. Las relaciones de poder estructural están basadas en unas referencias de flagrante iniquidad e injusticia. Los que detentan el poder sintético, infligen, al ejercerlo, la violencia estructural. Sus motivaciones éticas, se fundan en el egoísmo radical de individuos y grupos que tienen como fin único o primordial de dicho ejercicio de poder, la imposición violenta de sus intereses propios, como reflejo de sus valores personales de ambición y codicia. Por su parte, respecto a los individuos y grupos personales que sufren sus efectos, la violencia estructural, se manifiesta en la impotencia de ejercer sus mínimos derechos de bienestar material y espiritual, en la injusta pérdida de sus libertades fundamentales, de su autoestima, y en la máxima degradación de su dignidad ingénita, sus capacidades naturales de gozar de la seguridad y el autodesarrollo esenciales de todas las personas.

Como se indicó anteriormente al describir la naturaleza del conflicto, también la violencia estructural ahonda sus raíces naturales en la insatisfacción de algunas necesidades humanas básicas. Dicho de otro modo, esta violencia opresora impide, restringe o dificulta la realización de las posibilidades inherentes en todos los seres

6 Galthun es considerado el principal originador de esta nueva visión de la violencia estructural. Es de notar que el nuevo concepto es rechazado por muchos pensadores adscritos a las escuelas tradicionales. Un ejemplo significativo es la crítica de Sartori (pp. $213 \mathrm{ss)} \mathrm{a} \mathrm{la} \mathrm{que} \mathrm{llama}$ despectivamente para refutarla "crueldad social del mercado" ( p. 24) 
humanos. Imposibilita la culminación y actualización de los potenciales latentes en todas las personas y colectivos humanos. En suma, la violencia cierra las oportunidades de acceso a bienes y servicios, de primera necesidad para la sobrevivencia digna de las mayorías humanas.

Por lo tanto, este pensamiento social renovador deja bien sentado que la violencia se ejerce no sólo por medio de armas o instrumentos coercitivos como son la prisión o la tortura, la represión policial, la censura del pensamiento o la prohibición de expresiones públicas de disidencia en opiniones, intereses y valores. Es esta violencia el producto del mismo sistema de dominación global.

Aparte de esas manifestaciones crudas de la violencia social, también hay que reconocer otras consecuencias estructurales que no tienen menor importancia. Me refiero al hambre persistente y generalizada, al desempleo crónico, a las enfermedades congénitas, al analfabetismo mayoritario, a los índices elevados de mortalidad infantil, a las deficiencias nutritivas de síntomas epidémicos, a la supresión masiva de las identidades culturales en sus raíces étnicas o religiosas. En resumen, me refiero a la degradación universal de los valores morales, los cuales acarrean secuelas lamentables de desintegración de los tejidos sociales, manifestados en la erupción de la drogadicción, la delincuencia, las olas crecientes de refugiados y emigrantes y el narcotráfico internacional.

No es posible olvidar, las inmensas lacras heredadas de la violencia ecológica que ha quebrado, quizá para siempre, el equilibrio tenue de nuestro ecosistema, amenazando así inexorablemente la supervivencia misma de la biosfera que nos sustenta a todos.

Antes de concluir esta breve disquisición acerca de la violencia, de su naturaleza y sus categorías, será oportuno reiterar que toda violencia es intrínsecamente dañina y perniciosa. En contraposición con el conflicto, la violencia en sí no puede cambiar su naturaleza. Se puede aminorar y dominar parcialmente. Pero su naturaleza es nociva y no admite transformación.

Es un error pertinaz, el querer eliminar o solucionar e incluso resistir la violencia con más violencia, aunque sea de diferente signo. La violencia que se ha denominado reactiva, vengativa o compensadora es, además de perversa, ineficaz, porque su única finalidad es el causar daño. La destrucción es su sola justificación.

Más tarde se delinearán algunas directrices teóricas y prácticas que sirven para regular la defensa y la resistencia civil contra las opresiones violentas. Estas normas directivas, se basan en las ideas y estrategias derivadas principalmente del pensamiento gandhiano, sobre la no-violencia como una expresión positiva y dinámica del poder social, en contra de los poderes imperantes en nuestras relaciones globales.

\section{Teorías sociales del conflicto y la violencia}

Esta sección ofrece un conciso panorama de la evolución del pensamiento occidental, en sus repetidos intentos de explicar, con rigor sistemático, las pautas permanentes del conflicto $y$ la violencia que han aquejado históricamente, a las generaciones de seres humanos, en todo el globo. ${ }^{7}$

7 La referencia primordial en este tema es el libro citado de Sabine. También son útiles para el conflicto internacional los trabajos de RosenauDurfee, Chomsky, Holsti, Deutsch, Aron, Miller, Brown, Sklair, y Kauppi-Viotti. La perspectiva marxista clásica está bien fundamentada en Krippendorff. 
Diversos pensadores han interpretado estas experiencias omnipresentes, desde perspectivas que reflejan muy diferentes contextos disciplinarios y divergentes premisas ideológicas y culturales.

Dentro de esa vasta gama de perspectivas epistemológicas, deseamos esbozar, con trazos sinópticos y selectivos, algunas de las más representativas. La sicología social moderna, desde su peculiar óptica disciplinaria, insiste en un importantísimo componente delconflicto: la realidad radical de la alteridad. Es decir, la experiencia de la diferencia sustancial que todos detectamos entre cualquier entidad humana, sea individual o grupal, y cualquier otra entidad con la que necesariamente se interrelaciona. La alteridad es función de la innata sociabilidad que distingue a todos los humanos. La percepción y el descubrimiento de lo otro, lo distinto, lo ajeno, constituyen una primera raíz del conflicto potencial, que sólo se superará con la aceptación internalizada de su distinta identidad, y al mismo tiempo de su dignidad intrínseca. Esta aceptación consciente puede llevar al respeto y a la confianza mutua. Sobre esa base se pueden construir interacciones sociales de armonía y quizás hasta de amor.

Desde muy distintas ópticas, las teologías de cualquier doctrina religiosa han desarrollado teorías normativas, comúnmente dicotómicas, que explican las contradicciones evidentes entre el orden social deseable y los datos empíricos. Dichas normas religiosas, contienen imperativos morales fundados en las relaciones humanas y naturales con los poderes sobrenaturales, bien sea de cariz politeísta o monoteísta. Las normas teológicas interpretan las flagrantes discrepancias morales evidénciales en la generalidad de las conductas sociales, que son las que generan los conflictos y las violencias. De esas discrepancias obvias, han nacido las explicaciones maniqueas y la distinción agustiniana, entre la ciudad de Dios y la ciudad humana. También la visión orgánica de las conexiones jerárquicas que existen entre la ley divina y la ley natural, que gobernó el pensamiento social y político europeo durante muchos siglos. Asimismo nacieron un sinnúmero de explicaciones teológicas vigentes en muchas otras culturas religiosas ajenas a la tradición occidental, que tratan de dictar normas preceptivas que conduzcan al orden social y político.

Uno de los temas cruciales que se han repetido a lo largo de la historia del pensamiento socio-político, respecto al origen del conflicto y la violencia, se refiere a si son determinados o no, por alguna causa inexorable. Las corrientes deterministas, que no se funda en dogmas o creencias religiosas, ofrecen una variada gama de causalidades como fuentes del conflicto y la violencia. Para Freud, por ejemplo, todo el comportamiento humano incluyendo las relaciones sociales conflictivas y violentas, está determinado por fuerzas externas a la conciencia individual.

Para Marx, el conflicto y la violencia social tienen sus causas determinantes en la ley dialéctica del cambio histórico. El cambio es, por ende, inevitable y necesario. El cambio social está activado por la determinación del conflicto estructural que conduce al progreso socio-histórico, a través de la lucha de clases por el poder económico. El conflicto de las clases económicas antagónicas es, por tanto, un imperativo, material e histórico, que determina la evolución de las estructuras de producción económica. Las cuales, a su vez, determinan las superestructuras de poder social y político y las correspondientes ideologías que las representan. 
Para los ideólogos del liberalismo, tanto en la generación clásica como en la doctrina del neoliberalismo reinante en la actualidad de la globalización económica, el conflicto social está articulado por la competitividad que tiene como fin, maximizar el lucro individual por medio del mecanismo regulador de los mercados.

Dentro de las tendencias teóricas que han propugnado algunas otras variantes del determinismo, para analizar el origen del conflicto y la violencia social, predominan las escuelas filosóficas que han fijado las causas de esta determinación en una concepción particular sobre la naturaleza humana. En el campo de las ciencias sicológicas, por ejemplo, han proliferado diversas corrientes que, con matices algo diferente, han postulado que el conflicto y la violencia son manifestaciones ineludibles de las fuerzas biológicas que determinan la conducta humana. El conflicto y la violencia, nacen así de los instintos genéticos que gobiernan el comportamiento de cada ser humano y le compelen a activar su agresión innata hacia los demás animales humanos. Las relaciones sociales, son -según esta escuela- relaciones de antagonismo y pugna inexorables ${ }^{8}$.

En el campo de las ciencias sociales, las orientaciones determinísticas de las premisas sicológicas mencionadas, han sido incorporadas por prominentes pensadores, personificados por Hobbes y Spinoza. El supuesto radical del antagonismo social ingénito en la naturaleza humana $\mathrm{y}$, por ende, la ley del egoísmo universal fueron elevados a principio científica o axioma nuclear de la conducta humana. Esas premisas ideológicas fueron llevadas a sus últimas consecuencias lógicas por muchos pensadores sociales.

Estos supuestos, alcanzaron su epítome intelectual con Hobbes. A diferencia de muchos otros autores pertenecientes a la gran corriente del mal llamado realismo, que incluyen a Macchiavelli y a otros muchos escritores cuyo pensamiento esbozaremos enseguida, Hobbes intentó hacer una tarea rigurosamente científica, con base en los principios de la lógica deductiva. La ciencia social de Hobbes tenía como modelo la ciencia mecánica del movimiento y las estructuras espaciales de la geometría. Hobbes partía de ciertos axiomas sicológicos, fundados principalmente en el instinto de autopreservación y en la primacía de las emociones sobre la razón. Las emociones se manifiestan en estímulo, respuesta y reacción. Son puras expresiones de deseo y aversión.

Hobbes quiso explicar de esa manera y por ende regular el complejo universo de las relaciones sociales y políticas. El deseo instintivo era, por una parte, la fuente causal del valor. Lo favorable era automáticamente aceptado y lo adverso era automáticamente rechazado. Por otra parte, el deseo individual se convierte en la fuente exclusiva de la seguridad y del poder. En síntesis, Hobbes fue el primer teórico social que intentó construir una justificación científica del egoísmo como explicación racional del conflicto y la violencia. ${ }^{9}$

8 El llamado Manifiesto o Declaración de Sevilla (1986) contiene unos puntos de vista de gran solidez científica sobre los origenes naturales de la violencia. Este documento fue elaborado por un grupo amplio de famosos científicos que representaban muchas regiones y disciplinas. Fueron convocados por la UNESCO, a iniciativa del mexicano Santiago Genovés. El pensamiento de Genovés está sintetizado en su trabajo Sciencie and Peace: An Anthropological Integrative Approach, que fue escrito en homenaje a los sesenta año de Federico Mayor. La declaración de Sevilla proclama que es científicamente incorrecto decir que la violencia está arraigada en la naturaleza animal del ser humano o que sea una herencia biológica o una tendencia instintiva.

9 Ver Sabine (pp.455-76) especialmente 462-3. El autor también analiza profundamente la evolución axiológica del egoísmo desde Platón hasta los Mill, pasando por los epicureos, Maquiavelo, Locke, Helvetius, Rousseau y Bentham 
Como hemos señalado, la importancia de Hobbes en la historia de las ideas políticas radica no tanto en su contenido teórico sino en su conato de rigurosidad metodológica, de acuerdo con los modelos de la lógica deductiva. El contenido de sus ideas, concuerda con una ingente cantidad de autores que han propugnado, a lo largo de la historia, la centralidad del egoísmo individual como la fuente del devenir histórico y del progreso social y político de la humanidad.

Los orígenes históricos de la escuela "realista" en el pensamiento occidental se remontan a Polibio y Tito Livio. En sus pioneros análisis interpretativos de la historia, sobre todo en su contexto bélico, concluyeron que la evolución histórica está impulsada por la guerra como resultado de la búsqueda incrementada del poder y la seguridad armada. La guerra es, para ellos, la expresión ciega de las fuerzas del destino.

Es de notar que los fundadores de esta corriente del pensamiento, eran historiadores cuyo quehacer consistía en observar hechos empíricos e interpretarlos de acuerdo con las normas de la lógica inductiva. A ellos se puede añadir, en el pensamiento griego, la figura de Trasímaco en la República de Platón, quien describe el poder como el interés de los poderosos. En ese sentido, se puede decir que ellos fueron los pioneros intelectuales, entre los pensadores grecolatinos de la gran corriente teórica que se apropia indebidamente del análisis objetivo de la realidad y que ha predominado durante siglos, hasta los últimas décadas, entre los analistas de conflictos, particularmente en el ámbito de las relaciones interestatales.

Los teóricos del "realismo" preconizado por Macchiavelli y sus seguidores, han interpretado las interacciones sociales $y$ políticas desde el ángulo exclusivo del conflicto violento, la lucha por obtener y aumentar el poder. Sobre esta fase amoral de la consecusión de intereses y, por ende, del egoísmo personal y estatal, es necesario precisar que la dudosa objetividad de la realidad que se arrogan, está fundada en dichas premisas ideológicas. Los presupuestos que sustentan la concepción del "realismo" respecto al conflicto y la violencia se pueden resumir en los siguientes enunciados:

- El conflicto violento es la fuente suprema del poder $\mathrm{y}$, a su vez, el instrumento más apropiado para su consecución. Por ello, el conflicto violento es ineludible y se experimenta en todas las relaciones colectivas que son, intrínsecamente y en todas las esferas de actividad, relaciones jerárquicas de poder.

- El conflicto, que tiene sus raíces en la violencia y el poder, sólo puede resolverse por el uso violento del poder.

- En el ámbito de las relaciones internacionales, las más importantes y prácticamente las únicas dignas de estudio, son las manifestaciones de violencia y poder representadas por los Estados, como órganos exclusivos del poder soberano.

- El poder, sobre todo en las relaciones internacionales, se define primordialmente en términos de armas y materiales bélicos.

- El objetivo primario del poder militar es la destrucción y derrota del enemigo por medio de estrategias calculadas racionalmente.

En resumen, el axioma ideológico que fundamenta las doctrinas del "realismo científico", es la primacía suprema del 
poder, sobre todo el estatal, o su equivalente del interés y la seguridad nacional, que hay que adquirir, defender e incrementar a toda costa, por cualquier medio, incluyendo los medios violentos. Dicho axioma ideológico está fundado en el axioma ético de la primacía, de los intereses propios como valor supremo de la conducta social.

\section{Marco conceptual del conflicto y la violencia}

La discusión precedente ha versado sobre la naturaleza, tipología y orígenes del conflicto y la violencia, conforme a las interpretaciones dadas por diferentes corrientes del pensamiento social. Ahora vamos a delinear un marco complementario de referencia conceptual.

En la sociología moderna de orientación distinta de los marxistas o neomarxistas, despuntan tres autores que han estudiado, en detalle, el cambio social. Max Weber describe el conflicto como una relación social, en la que la acción interna se orienta intencionalmente a que un actor lleve a cabo su propia voluntad, contra la resistencia de uno o más actores. El conflicto será pacífico cuando no se emplee la violencia física, y así se manifiesta en competencia, es decir, en un intento no violento de controlar las oportunidades y ventajas que son deseadas, también por otros. La competencia es pues, un proceso regulado en cuanto sus fines y medios están orientados hacia la preservación de un determinado orden social. Esta lucha competitiva puede ser con frecuencia latente y se llama selección social o biológica, que es una condición social inevitable.
Dentro de su contexto teórico de funciones y estructuras que conforman las relaciones sociales, Weber concibe el conflicto como un mecanismo de cambio selectivo, pero que está siempre encaminado al mantenimiento estable del orden social. La solución del conflicto ha de situarse dentro del contexto estructural dominante. ${ }^{10}$

De un modo similar, Talcott Parsons recalca la importancia de mantener la estabilidad relativa y la constancia limitada de las uniformidades y pautas de interacción entre los elementos del sistema social. Las funciones sistémicas son los factores dinámicos que habilitan sus valores, con una orientación teleológica. Los procesos constituyen "la serie de condiciones necesarias para el desarrollo, integración, eficacia o disfunción del sistema". De ahí que Parsons concibe al cambio como generador de disfunción social en cuanto se opone a los fines básicos de desarrollo e integración funcional de los sistemas sociales ${ }^{11}$.

En contraste con sus dos predecesores, Ralf Dahrendorf acepta que el conflicto es un fenómeno inherente y dinámico, presente en todas las relaciones sociales. Más aún señala que el conflicto es el dinamismo interno y el motor mismo del cambio social. Además, siguiendo las tradiciones analíticas provenientes de Marx, por un lado, y por otro lado, de una larga serie de pensadores, como Mosca, Pareto, Michels y Quincy Wright, etc., que han estudiado la formación de las élites sociales.

Dahrendorf acepta que el conflicto social tiene sus raíces en la estratificación del

10 Ver sus conceptos relacionados a la acción social ( Theory p. 88) autoridad ( Ib. pp. 57, 295-301, 328) orden legítimo ( Ib. 57,124 ss, 130 ss, 324 ss ) y poder ( Ib. 152)

11 Ver la definición citada en Essays p. 218. Otras referencias importantes sobre la estructura social se pueden ver ( Ib. 54-6, 143-4, 165-8, 130-2, 239-40, 325-6 y ampliamente en pp. 348-69) funciones ( Ib. 217 ss, 224-37, 399-400) autoridad ( Ib. 249- 52, 409-12) y poder (Ib. 391 ss). 
poder individual y colectivo, representada por las oligarquías sociales. Las clases dominantes, (cuyo origen no está estrictamente ligado, como en Marx, a los estratos económicos) se oponen tajantemente al conflicto social, porque temen perder su status de prominencia y control. Por eso defienden, por todos los medios posibles, incluyendo la represión coercitiva y violenta, sus intereses. Defienden la conservación del sistema y de las normas autoritarias que vertebran la legitimidad del orden social constituido. Por ello, el cambio social, sólo es posible por las acciones de otros grupos sociales no oligárquicos que poseen suficiente poder. ${ }^{12}$

La visión del conflicto como agente del cambio social, también impulsa el pensamiento de muchos científicos que analizan las realidades contemporáneas, englobados en lo que se ha denominado

los estudios de la cultura de paz.

Según esta corriente conceptual, cuya prestancia intelectual aumenta paulatinamente, el conflicto es omnipresente, inevitable y constante. Pero el conflicto se puede transformar para convertirse en una fuerza impulsora del cambio social. La violencia es, por consiguiente, una mala solución del conflicto. Es nefasta, destructora, injusta e ineficaz. La solución idónea del conflicto, como eje positivo del cambio social, consiste en su transformación positiva y en el uso de estrategias no violentas que serán detalladas en nuestra última sección.

\section{Conflicto, violencia y desarrollo}

El conflicto transformado por medio de actividades no-violentas, no solamente se convierte en el motor del cambio social, sino también del desarrollo humano, entendido en un amplísimo sentido, que está repleto de múltiples consecuencias para el conocimiento y la acción social.

La noción de desarrollo social que propugnan los estudios sobrela paz, es la de un desarrollo humano integral. Desarrollo humano, es decir de todas las personas y comunidades englobadas en todos sus ámbitos de género, cultura, geografía; y ecología, a través de la vasta variedad de sus funciones vitales. Desarrollo social humano, es decir de la universalidad común de todas las entidades diversas: los géneros, las clases, las etnias, las nacionalidades y toda la inmensa gama de grupos de interés. Desarrollo social humano que aglutine las extensas e intensas redes de interdependencia que conectan a la humanidad con su entorno biosférico de la naturaleza, el cosmos, en su único ecosistema mundial compartido.

En este sentido, será el desarrollo social humano el que permita superar los límites artificiales del desarrollo económico, aunque sea sustentable, para alcanzar sus dimensiones holísticas de un desarrollo integral. Un desarrollo humano integral que incorpore la satisfacción equitativa de todas las necesidades básicas de todas las personas, de todos los intereses y valores, de todas las energías vitales, materiales y espirituales, de todos los derechos y deberes, y de todas las libertades.

El desarrollo humano integral es el paradigma central de la cultura de paz, como única solución viable del conflicto y la violencia. En las próximas páginas pasaré a delinear los vínculos que existen entre

12 Ver. Op. Cit. Passim. Para un tratamiento marxista del conflicto, aparte de las obras citadas, ver en el contexto latinoamericano las obras de Cerutti, Roig, Himkelammert y La Bastida. 
esta visión del desarrollo social y varios conceptos íntimamente interrelacionados con ella.

\section{Estrategia de la no-violencia}

Es evidente que los conflictos no transformados pueden fácilmente generar violencia. Esta tesis se aplica tanto a la violencia directa y personal perpetrada por individuos o por élites de poder, como a la más perniciosa violencia estructural. ${ }^{13}$

El tema de este análisis final, es el diseño de estrategias que ayuden a resistir, a defenderse, y últimamente a triunfar sobre las violencias sistémicas que victimizan a las amplias mayorías de la humanidad. Es ésta una tarea necesaria, en un mundo cuyas relaciones están imbuidas por estructuras globales de opresión explotadora que las hacen cruelmente injustas. Su contexto es la realidad hiriente de la actualidad histórica, la cultura global imperante del consumismo a ultranza, la exclusión de oportunidades, la privación masiva de posibilidades, la frustración sistemática de las expectativas de bienestar y sobrevivencia, la ausencia de libertades y de mecanismos de participación ciudadana.

Esta violencia estructural amenaza la desintegración social con el control coercitivo de las disidencias. Así se genera la tentación de adoptar la violencia colectiva como instrumento de liberación, de agitación y movilización para instaurar los urgentes cambios estructurales que se requieren en las relaciones del poder global.

Nuestra realidad contemporánea contiene los síntomas alarmantes de una auténtica crisis mundial. La turbulencia sistémica mencionada, se podría convertir en una hecatombe universal $\mathrm{y}$ en un proceso continuado de desintegración destructiva. Esto será inevitable a no ser que sepamos controlar la competencia desbocada por el control de recursos y mercados, las expansiones neo-colonialistas y la acumulación de armamentos.

Cunden las tentaciones recurrentes de acudir a la violencia como única arma estratégica eficaz, ofensiva y defensiva, para erradicar la violencia dominante. Contra estas tentaciones, se esbozan aquí algunos principios teóricos y prácticos de otra estrategia contra la violencia destructora. Una estrategia viable, eficaz y constructora.

Mi análisis de la estrategia de la defensa no violenta se inspira libremente en la lectura devarios autores, pero sobre todoen un libro excelente, publicado en 1996 por Robert Burrowes. ${ }^{14}$ El modelo estratégico clásico de Clausewitz propugna que la guerra, como expresión máxima del conflicto violento, es otro mecanismo político para maximizar el poder. La finalidad de la violencia es obligar al enemigo a cumplir la voluntad del poderoso.

La estrategia óptima es multiplicar el poder y aplicarlo en el lugar decisivo y

13 Las investigaciones de Galthun sobre este tema están documentadas idóneamente en Arenal pp. 339 nota 1 y 349 - 56 con sus notas correspondientes. El pensamiento fundacional sobre la estructura centro-periferia y la violencia del imperialismo está citado en las páginas 352 y 346.

La teoría de la dependencia como paradigma transnacional la comenta del Arenal pp. 309-37. Desde otras perspectivas y con particular énfasis en el desarrollo dependiente de América Latina, ver Werz Acerca del tema de la dependencia. (Ib. 122-35 y 234-45). También la dependencia es el nucleo de los estudios citados de Cerutti, Munck y Hinkelammert, y de los ensayos compilados en Democracia y Desarrollo en América Latina y en Los nuevos procesos sociales. Se debe añadir el excelente esfuerzo de divulgación contenido en el libro de Mac Gregor.

14 Aparte de esta obra ver otras perpectivas complementarias en Justice Without Violence, Rethinking Peace Y Approaches to Peace. Entre los varios contribuyentes se cuentan Sh. Brown, K. Schraub, P. Wehr, H. y G. Burgess, K. y A Boulding, I. Claude, P. Weil y G. Sharp. 
por medios decisivos. Algunos de estos principios estratégicos se pueden adoptar, una vez trasformado debidamente, a la defensa no violenta.

La estrategia de la no-violencia, mantiene la misma meta de dominar el poder y la voluntad del oponente. Son los medios y las motivaciones, así como los valores los que le dan un carácter radicalmente diferente de la estrategia violenta. Los cimientos conceptuales y éticos de la estrategia no violencia, son los principios enumerados a lo largo de esta exposición.

La sociedad humana se define como comunidad de valores compartidos. El conflicto radica en la insatisfacción de necesidades humanas innatas y universales. El poder es la capacidad de realizar, pero también la de resistir la agresión. De acuerdo con dichos principios, la estrategia no-violenta tiene el propósito de crear las condiciones de cambios en políticas, procesos, estructuras y sistemas, que sean capaces de satisfacer las necesidades humanas. Es preciso consolidar el poder y la voluntad social para resistir la agresión, alterando la voluntad del contrario. Así se lograrán crear las condiciones requeridas para debilitar su poder, a través del uso de acciones coercitivas no violentas. Estas acciones deben de atacar lo que Burrowes llama el centro de gravedad del adversario. Este centro de gravedad está compuesto por el conjunto limitado de aliados no hegemónicos que apoyan a las élites dominantes del sistema global.

El proceso de movilización social no violenta se funda, por consiguiente, en los postulados de la soberanía de la sociedad civil y en el propio poder social enraizado en la superioridad moral. La revolución social no-violenta se basa también en la concepción gandhiana del poder de la voluntad. Es decir, que la voluntad humana se proyecta como centro de gravedad del poder y de la unidad humana. La voluntad se actualiza dinámicamente como una expresión de identidad moral, de independencia y de auto-realización.

Sobre estos axiomas filosóficos y éticos, se consolidan los poderes de la resistencia, la defensa y la contra ofensiva no violenta. Es necesario reiterar que la no violencia no equivale en modo alguno a inactividad pasiva y a pacifismo inerme. La no violencia, impulsada por Gandhi y su discípulo Martin Luther King, es intrínsecamente activa. Es una dinámica usada para confrontar la violencia; no para ignorarla y evitarla.

La no- violencia expuesta aquí es una estrategia de acción, de protesta, de persuasión, de no cooperación y de intervención pacífica. Las tipologías de la estrategia de acciones no violentas son múltiples. Abarcan actos simbólicos de oposición pacífica como son las manifestaciones, vigilias, piquetes y huelgas. También comprenden numerosas actividades de desobediencia civil, boicoteos, negativas a pagar impuesto y a participar en elecciones fraudulentas.

Del mismo modo se incluyen otras muchas acciones, de bloqueos, ocupaciones de edificios, ayunos y encarcelamientos buscados. También abarcan la creación de mercado alternativos, cooperativas de producción y crédito, de escuelas y medios de comunicación paralelos.

Gene Sharp, otro eminente discípulo de Gandhi, señala varias categorías de la actividad no violenta: La resistencia selectiva, la reconciliación activa, la resistencia moral, la resistencia pasiva, la resistencia pacífica y la acción directa. Todas ellas reciben su impulso de la revolución fundada en la "SATYAGRAHA" (Verdad) de Candi. 
Esta dinámica verdad-voluntad-espírituenergía, es fuente de libertad, de conciencia, de servicio y de armonía con el propio ser, con la humanidad y con la naturaleza. La verdad gandhiana es, pues, la autorealización de todos los seres humanos autónomos y responsables. Esta verdad es amor y poder interior, desde dentro y sobre sí mismo. La estrategia no violenta propugna así mismo la acción coercitiva. Pero se trata de una coerción basada en la verdad y en el respeto a la dignidad compartida con las demás. Además esta coerción acepta el sufrimiento propio y no busca el castigo y la revancha personal o colectiva.

\section{Conclusiones}

Para concluir, voy a un breve esbozo de los principios claves de la acción de defensa estratégica, relacionados con los conflictos y las violencias mundiales:

- Las causas del conflicto y las violencias globales son las decisiones, procesos y estructuras del sistema global dominante, que imposibilitan la satisfacción de las necesidades básicas de las mayorías humanas.

- Estas causas son activadas por las elites hegemónicas del sistema global, con el apoyo activo de las elites nacionales.

- Los agentes sociales más importantes en el sistema de las relaciones mundiales no son los estados sino que son los grupos civiles de identidad, de género, de clase, de intereses, de etnias, de cultura, de religión y otros

- Los procesos de acción no violenta y de transformación de conflictos son lo únicos métodos eficaces para defenderse de la violencia estructural.

- El propósito central de la estrategia de la defensa no violenta es eliminar las causas estructurales de los conflictos violentos en las relaciones mundiales. Estas incluyen las dominaciones del patriarcado masculino, de los diversos imperialismos, de los socialismos totalitarios, de la globalización capitalista y de la soberanía absolutista de lo estados.

- Las comunidades sociales de todo el mundo deben usar las estrategias de defensa no-violenta para crear estructuras autónomas de poder social y político, que a través de redes integradas de interacción mundial, conduzcan eficazmente a una profunda reestructura del actual sistema de dominio global.

\section{Bibliografia}

ARENAL, del C. (1993). Introducción a las relaciones internacionales Tecnos.

ARON, A. R. (1963). Paz y guerra entre las naciones. Rev. de Occidente.

BURROWES, A. R. (1996). The Strategy of Non-violent Defense.

BLACK, A. (1966). The Dynamics of Modernizatio. Harper.

CURITIS, M. ed. (1964). The Great Political Theories, Avon.

CERRUTTI, A. H. (1992). Filosofía de la liberación latinoamericana FCE.

CHONSKI A. N. (1993). El nuevo orden mundial y Los vencedore. Txalaparta, Euzkadi.

DAHENDOFF, A R. (1959). Class and Class Conflict Stanford U.

DAHL, A. R. (1993). La democracia y sus críticos. Paidos. 
GANDARIAS, J ed. (1996). Mundialización y liberación. UCA Managua.

GALTUNG J. (1996) Peace by Peaceful Means Sage-IPRI.

GERTH y MILLS. ed.(1966). From Max Weber. Oxford U. Press.

GRASA, O. R. (1977). La resolución de conflictos.

GENOVES N. S. (1994). Science and Peace: An Anthropoligical Integrative Approach.

GIDDENS, A. (1993) Sociologia, Alianza, Ed.Madrid. España.

HINKELAMMERT, A. F. (1984) Crítica a la razón utópica. S.J. Costa Rica.

HOROWITZ, H.(1966). Three Worlds of Development. Oxford.

KOHN, H. (1960) The Idea of Nationalism. Mc Millan.

KRIPPENDORFF, N. (1985) Las relaciones internacionales como ciencia y El sistema internacional como historia. FGE.

LIPSET, S.M. (1975). Political Man.

LEFEBVRE, A.H. (1967). Lenguaje y sociedad B.A.

LEDERECH, J.P. (1996) Mediacion gernika, Euzkadi.

Mc GREGOR, F. (1989) Cultura de Paz. Lima.

MERLO, M. (1978). Sociología de las Relaciones Internacionales. Alianza ed.
MICHELS, R. (1962). Political Parties. Free Press.

NAVARRO, $\mathrm{K}$ y GERTEMBERG, $\mathrm{B}$ (1997). Introducción a la historia del pensamiento latinoamericano. Panamá.

PADILLA, L. A. (1992). Teoría de las Relaciones Internacionales. $\mathrm{La}$ investigación sobre la paz y el conflicto. IRIPAZ Guatemala.

PARSONS, T. (1965). Essays in Sociological Theory. Free Press.

QUAN O B. y M. HOOD Modelo de la historia natural del conflicto

REYNOLDS, P. (1977) Introduccion al estudio de las Relaciones Internacionales.

ROIG, A.A. Teoría y Crítica del pensamiento latinoamericano

SIMON, Y. (1964). Philosophy of Democratic Government Chicago U Press.

SABINE, G.H (1966). A History of political Theory $3^{\circ}$ ed,

SARTORI, G. (1993). ¿Qué es la democracia? D.E México.

SKLAIR L.(1972). Sociology of the Global System. UNESCO (1993). Programa Cultura de Paz. San Salvador.

WEBER, M (1965). The Theory of Social and Economic Organization. Free Press.

WERZ, A. (1991). Pensamiento socio-político moderno en América Latina. Nueva Sociedad. 